\title{
Utilizando técnicas de ensino participativas como instrumento de aprendizagem e sensibilização do manejo da lactação para profissionais de enfermagem de uma maternidade*
}

\author{
Utilizing teaching techniques like instrument to apprentceschip and sensitive of profissionals of mater- \\ nity about lactation management
}

\author{
Utilizando técnicas de enseñanza como instrumento para el aprendizaje y sensibilización de funcionarios \\ de una maternidad referente al manejo de la lactación
}

\section{Patricia Luciana Moreira ${ }^{1}$, Márcia Regina Cangiani Fabbro ${ }^{2}$}

\begin{abstract}
RESUMO
Para promover, proteger e apoiar o aleitamento materno, o profissional de saúde precisa adquirir e incorporar, além do conhecimento em aleitamento materno e competências clínicas, habilidades de comunicação para interagir com a nutriz. Descrever uma proposta educativa para o manejo e incentivo do aleitamento materno a profissionais da equipe de enfermagem de uma maternidade do interior de São Paulo. A metodologia utilizada consistiu em aulas expositivas dialogadas, dinâmicas de grupo, dramatização e debates com o objetivo de estimular um olhar crítico e amplo, abarcando aspectos sociais, culturais, econômicos que envolvem a amamentação e que propiciem ao profissional uma reflexão sobre sua prática profissional. Além destes, utilizamos pré e pós-teste, auto-testes e a prática clínica. Os resultados satisfatórios tanto no pré-teste, pós-teste e auto-teste como na participação efetiva dos envolvidos com os trabalhos nos mostram que uma proposta educativa que privilegie uma maior participação e interação mostrou-se eficaz para abordar temas complexos que envolvem múltiplos aspectos como o aleitamento materno. Acreditamos que mudanças nas práticas de saúde não dependem também da sensibilização deste profissional para incorporar estes conhecimentos a sua prática profissional.
\end{abstract}

Descritores: Aleitamento materno; Equipe de enfermagem; Educação continuada

\begin{abstract}
To promote, protect and support the breastfeeding, the health professional needs to acquire and to incorporate, beyond the knowledge in breastfeeding and clinical competences, abilities of communication to interact with the wet-nurse. To describe an educative proposal for the handling and the incentive for the act of the breastfeeding to the professionals of the team of Licensed Practical Nurse of a maternity hospital in the inland of São Paulo state - Brazil. The methodology that was used consisted of expositive dialogued classes, group dynamics, dramatization and debates with the objective to stimulate a critical and wide look, embracing social, cultural, economical aspects that involve breastfeeding and that provide the professional a reflection on his own professional practicals. Besides these, we used pre-test, post-test, self-test and clinical lecture. The satisfactory results in as much as in the pre, post and self-tests as in the effective participation of the ones involved with the jobs show that an educative proposal that gave privileges to a larger participation and interaction was shown effective to approach complex themes that involve multiple aspects as the maternal breastfeeding. We believe that changes in the practicals of health depend also on the sensitization of this professional to incorporate these knowledges to his professional practicals.
\end{abstract}

Keywords: Breast feeding; Nursing, team; Education, continuing

\section{RESUMEN}

Para promover, proteger e apoyar la lactancia materna, el profesional de salud necesita adquirir e incorporar, además del conocimiento en lactancia materna y competencias clínicas, habilidades de comunicación para interaccionar con la nodriza. El artículo presente tuvo como objetivo describir una propuesta educativa para el manejo e incentivo de la lactancia materna para profesionales del equipo de enfermeros de una maternidad del interior del estado de São Paulo. La metodología utilizada consistió en clases expositivas dialogadas, dinámicas de grupo, dramatización y debates con el objetivo de estimular la mirada crítica y amplia, abarcando aspectos sociales, culturales, económicos que envuelven la lactancia y que propicien al profesional una reflexión sobre su práctica profesional. Además de estos, utilizamos pré y post-evaluación, autoevaluación y la práctica clínica. Los resultados satisfatorios tanto en la pré, post y autoevaluación como en la participación efectiva de los envolvidos con los trabajos nos muestran que una propuesta educativa que privilegie una participación e interacción más grande se mostró eficaz para abordar temas complejos que envuelven múltiplos aspectos como el de la lactáncia materna. Creemos que cambios en las prácticas de salud dependen también de la sensibilización de este profesional para incorporar estos conocimientos a su práctica profesional.

Descriptores: Lactancia materna. Grupo de enfermería. Educación continua.

\footnotetext{
* Este artigo fer.parte de um projeto encaminhado no ano de 2000, ao Programa de Bolsa Treinamento da Pró-Reitoria de Graduacão da Universidade Federal de São Carlos - UFSCAR - São Carlos (SP), Brasil.

${ }^{1}$ Enfermeira.

${ }^{2}$ Professora Assistente do Curso de Graduação em Enfermagem da Universidade Federal de São Carlos - UFSCAR - São Carlos (SP), Brasil.
} 


\section{INTRODUÇÃO}

Amamentar é um fenômeno complexo, influenciado por aspectos culturais, sociais, psíquicos e biológicos. Muitos estudos têm contribuído para os avanços no conhecimento desta prática e suas vantagens hoje são mundialmente conhecidas. Dada a superioridade do leite materno sobre seus pretensos substitutos, provada por um amplo referencial teórico, atualmente o leite materno é considerado alimento ideal para o crescimento e desenvolvimento das crianças até 4 a 6 meses.

As políticas em prol desta prática, iniciadas na década de 70 culminaram com estratégias reducionistas com enfoque biológico e num discurso ideológico em que a mulher seria a figura principal pela saúde da criança. A década de 90 se caracteriza por um repensar este paradigma. Trouxe a necessidade de focalizar a amamentação com as lentes da relação promoção - proteção - apoio e estabeleceu um novo foco sobre a mulher ${ }^{(1)}$. Nota-se então, que as políticas em prol desta prática já aumentaram cerca de dez vezes na prevalência do aleitamento materno exclusivo em crianças de 0 a 4 meses ${ }^{(2)}$.

Contudo, não basta à mulher estar informada das vantagens do aleitamento materno e optar por esta prática. Ela precisa estar inserida em um ambiente favorável à amamentação e encontrar apoio no profissional de saú$\mathrm{de}^{(3)}$. Como o início da lactação ocorre freqüentemente no hospital, é de responsabilidade do profissional de saúde, dentre eles a equipe de enfermagem, proporcionar às mães orientações e conhecimentos técnicos e demonstrar interesse à prática da amamentação, criando um clima afetivo com o binômio mãe-filho.

Os profissionais de saúde, por meio de suas atitudes e práticas, podem influenciar positiva ou negativamente o início da amamentação e sua duração(4).

O aumento nas taxas de amamentação é, em parte, determinado pela capacitação dos profissionais de saúde ${ }^{(5)}$. Estudos evidenciam que treinar e capacitar profissionais de saúde em hospitais para a promoção do aleitamento materno resulta no aumento do tempo de amamentação. O conhecimento sobre os diversos aspectos desta prática proporciona ao profissional atitudes positivas e práticas corretas em seu benefício $^{(6)}$. Desta forma, a intervenção educativa tende a se tornar um fator em potencial para o estímulo do aleitamento materno ${ }^{(7)}$.

Porém, estudos recentes apontam a necessidade de expansão das atividades de promoção, incentivo e apoio ao aleitamento materno no Brasil ${ }^{(8)}$. Apesar da tendência crescente da prática da amamentação apontadas nas pesquisas, ainda não alcançamos os índices recomendados pela Organização Mundial de Saúde, ou seja, de aleitamento materno exclusivo até os 6 meses e parcial até os 2 anos ou mais de vida ${ }^{(9)}$.
Muitos cursos priorizam os aspectos técnicos e biológicos do aleitamento materno, o que restringe a visão do aluno e do profissional, deixando de contemplar as reflexões sobre as atitudes e crenças da amamentação ${ }^{(10)}$. Desta forma, a formação exclusivamente técnica não permite que o profissional pratique e desenvolva as habilidades de questionar e refletir acerca do assunto.

$\mathrm{O}$ aleitamento materno não pode ser visto pelos trabalhadores da saúde como um ato puramente biológico e altruísta, em que a mulher tem que se despojar de todos os seus valores para concretizá-lo. Esta visão, desvinculada da realidade, não colabora para o estabelecimento do processo de amamentação ${ }^{(11)}$.

A nosso ver, este profissional precisa não só estar de posse de conhecimentos e habilidades, mas suficientemente sensibilizado para incorporá-las em sua prática profissional. Dada a carência de trabalhos que se propõe a descrever o enfoque metodológico de uma proposta educativa, o presente trabalho teve como objetivo descrever uma proposta educativa para o manejo e incentivo do aleitamento materno a profissionais da equipe de enfermagem (auxiliares e técnicos) de uma maternidade do interior de São Paulo, onde foram utilizadas técnicas de sensibilização que proporcionem ao profissional uma reflexão sobre sua prática e uma conscientização de suas atitudes tomando como referência a assistência e o cuidar individualizado e humanizado.

\section{MÉTODOS}

As atividades foram desenvolvidas no período de 24 de abril de 2000 a 7 de junho de 2000 em uma maternidade do interior do Estado de São Paulo. Participaram da proposta educativa 17 profissionais de enfermagem (auxiliares e técnicos) que não haviam recebido nenhum treinamento sobre o aleitamento materno, mediante autorização da coordenação de enfermagem da instituição.

Antes de iniciarmos a prática educativa, aplicamos um questionário constituído de 19 questões fechadas e 2 questões abertas relacionadas aos diversos aspectos do aleitamento materno, denominado pré-teste, que teve como finalidade identificar dúvidas e necessidades da equipe e que também foi aplicado ao término do curso, enquanto forma de avaliação dos conhecimentos teóricos (pós-teste).

A prática educativa foi composta por 10 aulas teórico-práticas, cujos temas foram: "Histórico e benefícios da amamentação; desmame precoce; fatores que influenciam no aleitamento materno; anatomia e fisiologia da mama, composição do colostro e leite maduro; início da amamentação e avaliação da mamada; dificuldade em relação à pega e bebês que exigem cuidados especiais; problemas precoces e tardios com as mamas; retirada e armazenamento do leite materno, apoio a nutriz após alta hospitalar; legislação e responsabilidade profissio- 
nal". A duração foi de 1 hora cada, sendo repetidas em dois dias, visando à flexibilidade de horário para que um maior número de funcionários pudessem participar. Os assuntos foram agrupados de acordo com a afinidade entre os temas e foram selecionadas técnicas de ensino que viabilizassem uma participação mais efetiva do grupo e a troca de experiências, conhecimento, reflexões e conscientização do grupo. Ao término de cada aula, foi aplicado um auto-teste, a fim de verificar se o conteúdo da aula havia sido assimilado. Os mesmos eram corrigidos e devolvidos na aula seguinte com as considerações pertinentes por escrito.

Ao término das aulas teórico-práticas, foi realizada a prática clínica do curso, com duração de 3 horas, sendo estas divididas em dois dias de 1 hora e 30 minutos cada, sob supervisão e acompanhamento das autoras deste trabalho.

\section{UTILIZANDO TÉCNICAS DE ENSINO PARTICIPATIVAS COMO UM INSTRUMENTO PARA SENSIBILIZAÇÃO}

Entendemos capacitação como um processo essencialmente ativo que envolve mudancas no modo de pensar, sentir e agir dos individuos e pelo qual eles adquirem, mudam ou reforçam conhecimentos, atitudes e práticas condizentes à saúde ${ }^{(12)}$.

Além disso, a capacitação visa uniformizar as informações de forma que toda equipe possa assistir, orientar e avaliar da mesma forma, sem dicotomia ou divergência de informações ${ }^{(13)}$.

Considerando a importância destas considerações direcionamos nossas estratégias de ensino utilizando técnicas que envolvessem dinâmicas de grupo, dramatizações, painéis, estudos de caso e debates. Estes exercícios permitem criar impactos nos participantes do grupo, conscientizando-os e sensibilizando-os para comportamentos e atitudes que dificultam o relacionamento interpessoal.

Isto é possível quando se estimula o participante a resgatar e refletir suas experiências ${ }^{(14)}$. Acreditamos que através das técnicas, as pessoas podem descobrir-se na sua identidade e nos seus valores, e nos grupos acontecem formas mais humanas e construtivas de convivência ${ }^{15}$.

A seguir descreveremos as estratégias utilizadas.

\section{Resgatando a experiência de amamentar}

No primeiro encontro do curso, que contou com a participação de 14 profissionais, aproveitando o momento de apresentação dos participantes através da técnica denominada "Apresentação Simples", lançamos a seguinte questão: "Quem entre vocês já passou pela situação de amamentar?". Como nem todos os participantes tinham filhos ou haviam amamentado, a estes foi proposto resgatar situações com pessoas próximas (amigos e familiares). As experiências iam sendo relatadas, e a partir delas, exploramos não apenas as facilidades ou dificuldades, mas também os sentimentos que eram gerados em torno desta experiência. De acordo com a perspectiva dos participantes, o período da amamentação é envolvido por momentos tanto de alegria e prazer quanto de insegurança, medo, conflitos e ansiedades. Esta técnica, que teve duração de aproximadamente 40 minutos, permitiu que os participantes percebessem a importância de refletir sobre si mesmo e suas experiências, dada a importância da auto-percepção para a interação com o outro. Fomos, então resgatando alguns fatores sociais, culturais e emocionais que se relacionam à amamentação. Após, abordamos o tema: "Histórico, benefícios da amamentação e desmame precoce".

\section{Estudo de caso: a realidade na sala de aula}

No segundo encontro tivemos a participação de 14 profissionais e utilizamos a técnica de ensino Estudo de Caso na aula denominada "Fatores que influenciam positiva e negativamente o aleitamento materno". Esta técnica permite apresentar ao grupo uma situação, seja ela real ou fictícia, para ser discutida, possibilitando o desenvolvimento de uma capacidade analítica e espírito científico, bem como a tomada de decisões. Além de retomar conceitos teóricos, os estudos de caso permitem relacioná-los com a prática através da observação de uma dada realidade.

Apresentamos o estudo de caso na forma da seguinte situação: a narração de uma jovem submetida a um parto longo e doloroso. Ela recebeu poucas informações da equipe da maternidade e tem dificuldades ao amamentar. O filho que demorou horas para ser a ela levado ${ }^{(16)}$. Após a apresentação da situação, pedimos para que os participantes apontassem práticas e situações que poderiam interferir no aleitamento materno e fomos escrevendo-as na lousa. Então, retomamos os conceitos e fatores apresentados durante a aula relacionando-os aos aspectos apontados.

Como o Estudo de Caso possibilita também uma discussão em grupo, levantamos a questão: "Como você, enquanto membro da equipe, poderia ajudar esta jovem?" Após uma discussão, os membros do grupo identificaram uma série de questões: a importância de prestar uma assistência individualizada à mulher, olhando essa mãe em sua singularidade, seus medos e anseios; proporcionar um clima de apoio, tranqüilidade e segurança de forma que esta mãe olhe o profissional como alguém em quem confiar e partilhar suas dúvidas de forma a aliviar o estado de ansiedade decorrente de conflitos internos pela (in) capacidade/ (ina)habilidade de amamentar; criar condições para que a mãe e bebê iniciassem os primeiros contatos o mais precocemente possível (por exemplo, na sala de parto).

\section{Sentir o outro através da Dramatização}

A dramatização, além de desenvolver a liberdade de expressão, proporciona ao participante imaginar-se em um papel que não é dele e sentir este papel. Esta técnica 
também contribui para desenvolver formas de comunicação $e$ expressão do aluno, ao mesmo tempo em que ativa esquemas de assimilação e assim aperfeiçoa o raciocínio indutivo e dedutivo ${ }^{(17)}$.

Neste encontro o tema proposto era "Orientando a amamentação" e os conteúdos abordados foram: "estimulando o contato do binômio na primeira hora após o parto", "postura profissional e a criação de um ambiente agradável para orientar a mãe" e "ajudando a mãe nas primeiras mamadas". O exercício foi desenvolvido informalmente, sem roteiro escrito. Foi proposta a seguinte situação para ser dramatizada: Um profissional levando o bebê para a mãe pela primeira vez após o parto.

Assim, os 16 participantes deste terceiro encontro, em duplas, assumiram os papéis de profissional e de mãe. Após o término da tarefa, cada um expôs como se sentiu em seu papel. O profissional relatava suas dificuldades, como a mãe foi abordada, o que sentiu que faltou na orientação, entre outros aspectos. Então, passamos a discutir sobre algumas posturas e condutas importantes para o profissional ao aconselhar a mãe, como ajudá-la a expressar seus sentimentos, demonstrar que deseja ajudá-la, falar baixo e calmamente, evitar palavras como problemas e fracasso. Por fim, após discutir cada comportamento, identificamos os que deveriam ser reforçados. Dessa forma, a dramatização foi uma estratégia de ensino que possibilitou discutir a inter-relação profissional-cliente através da reflexão sobre estar no papel do outro, relacionando às condutas praticadas no seu cotidiano.

\section{Identificando sinais: A utilização do Painel como dinamização de grupo}

Esta técnica foi utilizada para discutir os vários aspectos relacionados à avaliação da mamada, visando a identificação de sinais positivos, ou seja, aqueles que indicam que o aleitamento está sendo bem sucedido e de sinais negativos, ou seja, de possíveis dificuldades na condução da mamada. Optamos pela montagem de um painel. No encontro havia 10 participantes e a técnica teve a duração de 30 minutos.

O painel foi dividido em duas partes: a primeira englobou sinais positivos e a segunda, sinais negativos que podem ser identificados na avaliação da mamada. Os sinais eram referentes a posição corporal da nutriz , respostas do bebê, estabelecimento de laços afetivos entre a mãe e o bebê, aparência da mama e "pega" do bebê. Cada sinal positivo tinha um respectivo sinal negativo a ser identificado. Por exemplo: referente à posição corporal, um dos sinais positivos é a mãe estar relaxada e confortável. Seu respectivo sinal negativo apontava a mãe com ombros tensos e inclinada sobre o bebê.

Terminada a montagem do painel, os participantes puderam ter a visão global de todos os aspectos que podem interferir na avaliação de uma mamada. Além disso, sua confecção possibilitou a integração dos parti- cipantes do grupo que, informalmente, discutiam entre si e se ajudavam a relacionar os sinais positivos e negativos acerca de cada situação.

\section{Solução de Problemas: discutindo vários} aspectos acerca de um mesmo tema

Para discutirmos o tema "Dificuldades e obstáculos à amamentação", os profissionais participaram da técnica denominada "Solução de Problemas", que permite estimular a reflexão acerca de um determinado problema a fim de alcançar uma solução apropriada. A fim de que a aula se tornasse ainda mais dinâmica, utilizamos quebra-cabeças que, após serem montados, apresentavam a dificuldade a ser solucionada. Para trabalharmos com o problema apresentado, o grupo foi dividido e cada um ficou responsável por um quebra-cabeça. Após a montagem, cada grupo discutiu as possíveis soluções para aquela dificuldade. Por fim, os grupos apresentaram os materiais e todos puderam refletir sobre as condutas para cada caso. A atividade teve duração de 30 minutos.

\section{Debate: oportunidade de crescimento}

Com o intuito de proporcionar aos participantes uma troca de experiência sobre um determinado assunto, este encontro utilizou como técnica de ensino o Debate, visando estimular o raciocínio e o pensamento crítico, além de ampliar a visão do aluno sobre determinado tema, discutindo-o a partir de diferentes pontos de vista.

Para que os temas do debate emergissem de um contexto mais próximo à realidade das mães e como uma forma de resgatar os conteúdos até então abordados no curso, solicitamos aos participantes que simulassem uma situação em que as mães aguardavam algum atendimento e enquanto isso conversavam sobre suas dificuldades em relação à amamentação. Desta forma, todos os participantes tiveram a oportunidade de encenar e debater.

Desta simulação surgiram os seguintes temas: questões sócio-econômicas envolvidas com o aleitamento materno, aspectos emocionais da mulher que amamenta, a influência da família no estímulo ou não do aleitamento materno e do desmame precoce, os problemas precoces e tardios com a mama e a importância da equipe de saúde e dos grupos de apoio durante o período do aleitamento materno. Os temas corresponderam aos conteúdos abordados nos outros encontros e embasaram o debate.

\section{A Dinâmica de Grupo como um método de perceber o "eu" e o "nós"}

A técnica que utilizamos no último encontro no qual abordamos o tema "Responsabilidade profissional no contexto do aleitamento materno" foi a dinâmica de grupo, não apenas como um meio de estimular a descontração entre os participantes, mas principalmente para estimular o espírito de equipe e a interação do 
grupo a partir da percepção individual e a importância do papel de cada um no grupo. Na dinâmica de grupo, "às pessoas é oferecida a experiência da mudança no relacionamento, na forma de comando, na liderança, na comunicação, na auto-imagem, na descoberta de si" ${ }^{(15)}$, havendo ainda a possibilidade de estimular habilidades de relação/interação entre os componentes do grupo, comunicação e percepção de si próprio. As dinâmicas de grupo, desta forma, incentivam a participação ativa do aluno no seu grupo, a transmissão e troca de pensamento e idéias, proporcionando ao aluno explorar, a partir da sua individualidade a convivência com o outro.

Assim, escolhemos a seguinte dinâmica ${ }^{(18)}$ : os participantes foram instruídos a sentirem seu corpo, dos pés à cabeça, ao andarem livres pela sala. Então, sentaram-se em duplas para, de olhos fechados, sentir as mãos do parceiro, imaginando o quanto elas trabalhavam. Após esta fase, solicitamos que imaginassem um objeto ou algo muito precioso para eles e o oferecessem ao colega com quem estava de mãos dadas.

Ao término da dinâmica, cada participante relatou o que sentiu, como sentiu seu corpo e como se sentiu dando algo importante de si para outra pessoa. Os participantes relataram sua experiência com entusiasmo, expondo seus sentimentos. Terminada a dinâmica salientamos o quanto cada indivíduo é importante para o grupo nos diversos ambientes, inclusive o de trabalho e a importância de dar o melhor de si mesmo e de valorizar o trabalho do outro.

\section{RESULTADOS}

Os resultados do pré-teste mostraram $86,95 \%$ de respostas corretas e 13,05\% de respostas incorretas. Já no pós-teste, a porcentagem de respostas corretas correspondeu a $95,72 \%$. Os números comprovam uma maior compreensão do processo do aleitamento materno, já que as questões abordavam os diversos aspectos trabalhados nos encontros. Vale ressaltar ainda que as dúvidas e necessidades da equipe abordadas nas 2 questões abertas do pré-teste foram consideradas no planejamento do curso, o que acreditamos ter aumentado o interesse e a participação do grupo. Quanto aos auto-teste, realizados ao final de cada aula, notamos índices de respostas incorretas muito baixo, o que consideramos ser um resultado satisfatório.

\section{REFERÊNCIAS}

1. Almeida JAG. Amamentação: um híbrido natureza e cultura. Rio de Janeiro: FIOCRUZ; 1999.

2. Rea MF. Reflexões sobre a amamentação no Brasil: de como passamos a 10 meses de duração. Cad Saúde Pública. 2003; 19(Supl 1):537-45.

3. Giugliani ERJ, Lamounier JA. Aleitamento materno: uma contribuição científica para a prática do profissional de saúde. J Pediatria. 2004;80(5):117-8.
Para avaliação do curso como um todo, utilizamos a escala de satisfação por expressões faciais (insatisfeito, pouco satisfeito, parcialmente satisfeito, satisfeito, muito satisfeito). Enquanto resultado, obtivemos respostas que variaram de "satisfeito" a "muito satisfeito".

\section{CONSIDERAÇÕES FINAIS}

O presente trabalho descreveu algumas estratégias de ensino que podem ser utilizadas para discutir conhecimentos, atitudes e práticas de profissionais de enfermagem acerca do manejo do aleitamento materno, entendendo-o não somente pelos aspectos técnicos e biológicos, mas contemplando também reflexões sobre as atitudes e crenças da amamentação tanto de quem assiste como daquele que é assistido.

As técnicas de ensino nos permitiram um estímulo constante quanto a participação de cada componente do grupo, permitindo que eles trouxessem suas experiências, refletissem e questionassem sobre suas condutas, percebendo gradativamente o seu contexto de uma forma mais global, seu papel e sua importância nele. Percebíamos, a cada aula, uma motivação maior de quem as freqüentava. A troca de informações ocorria sempre que lhes era solicitado dar opiniões, falar de suas experiências, de suas limitações. Tal fato ocorria, inclusive, durante as aulas expositivas dialogadas, nas quais eles davam exemplos práticos do que lhes transmitíamos teoricamente. Instigamos nos participantes a necessidade de preocupar-se com a qualidade da assistência prestada ao binômio e com suas próprias atitudes mediante o processo de amamentar.

Uma proposta educativa que privilegia a utilização de um enfoque metodológico participativo mostrou-se eficaz para abordar temas complexos que envolvem múltiplos aspectos como no aleitamento materno e foi um instrumento que pode contribuir para conscientização, libertação e sensibilização do grupo, o que acreditamos ser de fundamental importância no estímulo de uma prática de aconselhamento em aleitamento materno que efetivamente compreenda a mãe de forma individualizada e humanizada. Assim, podemos dizer que iniciativas que contemplem todos estes aspectos do amamentar podem contribuir significativamente para a mudança das práticas de saúde dos serviços que atendem o binômio mãe-filho.

4. Carvalhaes MABL, Corrêa CRH. Identificação de dificuldades no início do aleitamento materno mediante aplicação de protocolo. J Pediatria. 2003;79(1):13-20.

5. Garduño AGH, Ruiz LR. Capacitación sobre lactancia materna al personal de enfermería del Hospital General de México. Salud Pública México. 2000;42(2):112-7.

6. Taddei JAAC, Westphal MF, Venancio SI, Bogus C, Souza S. Breastfeeding training for health professionals and resultant 
changes in breastfeeding duration. Rev Paul Med. 2000; 118(6):185-91.

7. Martens PJ. Does breastfeeding education affect nursing staff beliefs, exclusive breastfeeding rates, and Baby-Friendly Hospital Initiative compliance? The experience of a small, rural Canadian hospital. Hum Lact. 2000;16(4):309-18.

8. Venâncio SI, Escuder MML, Kitoko P, Rea MF, Monteiro CA . Frequência e determinantes do aleitamento materno em municípios do Estado de São Paulo. Rev Saúde Pública. 2002; 36(3):313-8.

9. Venâncio SI. Dificuldades para o estabelecimento da amamentação: o papel das práticas assistenciais das maternidades. J Pediatria. 2003;79(1):1-2.

10. Silva IA. Construindo o significado da amamentação a partir da assistência de enfermagem. Rev Bras Enferm. 1998;51(2): 217-30.

11. Silva IA. Amamentar. uma questão de assumir riscos ou garantir benefícios. São Paulo: Robe; 1997.

12. Pinto LM, Vitolo MR, Grota MB, Baxter P, Mori CF, Silva AC, Estudo comparativo entre diferentes abordagens educativas no sistema de alojamento conjunto. Rev Ciênc Med. 1998;7 (3):95-102.

13. Campestrini S. Alojamento conjunto e incentivo à amamentação. Curitiba: EDUCA; 1983.

14. Fritzen SJ. Janela de Johari. Petrópolis: Vozes; 1986.

15. Andreola BA. Dinâmica de grupo. Petrópolis: Vozes; 1982.

16. Ministério da Saúde. Programa Nacional de Incentivo ao Aleitamento Materno. Curso de 18 horas para equipes de enfermagem de maternidades. Brasília (DF): Ministério da Saúde; 1993.

17. Antunes C. Técnicas pedagógicas de dinâmica de grupo. São Paulo: Ed. Brasil; 1974.

18. Fritzen SJ. Exercícios práticos de dinâmica de grupo. Petrópolis: Vozes; 1990. 